\title{
Occupational therapy for multiple sclerosis (Review)
}

Steultjens EEMJ, Dekker JJ, Bouter LM, Cardol MM, Van den Ende ECHM, van de Nes J



\section{THE COCHRANE COLLABORATION $^{\circledR}$}

This is a reprint of a Cochrane review, prepared and maintained by The Cochrane Collaboration and published in The Cochrane Library 2009, Issue 1

http://www.thecochranelibrary.com

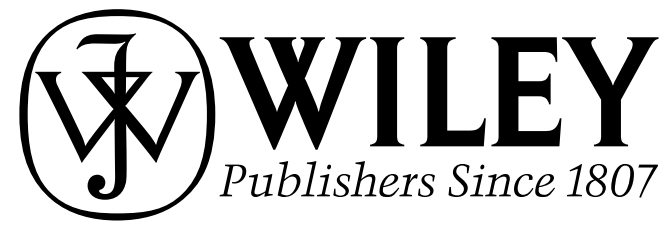

Occupational therapy for multiple sclerosis (Review)

Copyright $\odot 2009$ The Cochrane Collaboration. Published by John Wiley \& Sons, Ltd. 
TABLE OF CONTENTS

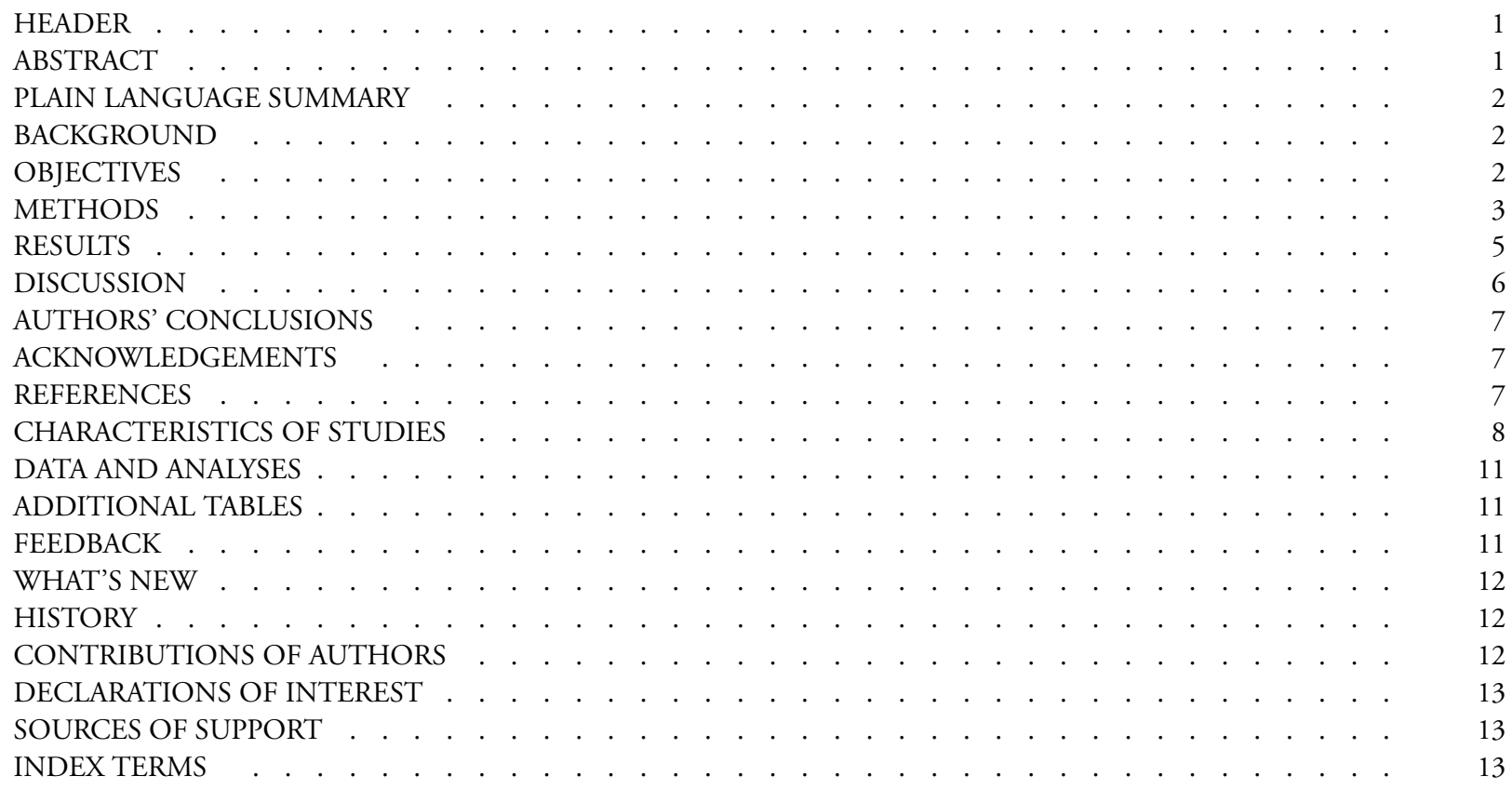




\title{
[Intervention Review]
}

\section{Occupational therapy for multiple sclerosis}

\author{
Esther EMJ Steultjens ${ }^{1}$, Joost J Dekker ${ }^{2}$, Lex M Bouter $^{3}$, Mieke M Cardol $^{4}$, Els CHM Van den Ende ${ }^{5}$, Jos van de Nes ${ }^{6}$
}

${ }^{1}$ Ergologie, Zeist, Netherlands. ${ }^{2}$ Department of Rehabilitation Medicine, Institute for Research in Extramural Medicine (EMGO), VU University Medical Center, Amsterdam, Amsterdam, Netherlands. ${ }^{3}$ Executive Board of VU University Amsterdam, Amsterdam, Netherlands. ${ }^{4}$ Nivel, Utrecht, Netherlands. ${ }^{5}$ Department of Rheumatology, Sint Maartenskliniek, Nijmegen, Netherlands. ${ }^{6}$ School of Occupational Therapy, University of Professional Education Amsterdam, Amsterdam, Netherlands

Contact address: Esther EMJ Steultjens, Ergologie, Krakelingweg 73, Zeist, 3707 HS, Netherlands. e.steultjens@ergologie.nl.

Editorial group: Cochrane Multiple Sclerosis Group.

Publication status and date: Edited (no change to conclusions), published in Issue 1, 2009.

Review content assessed as up-to-date: 21 May 2003.

Citation: Steultjens EEMJ, Dekker JJ, Bouter LM, Cardol MM, Van den Ende ECHM, van de Nes J. Occupational therapy for multiple sclerosis. Cochrane Database of Systematic Reviews 2003, Issue 3. Art. No.: CD003608. DOI: 10.1002/14651858.CD003608.

Copyright (C) 2009 The Cochrane Collaboration. Published by John Wiley \& Sons, Ltd.

\section{A B S T R A C T}

\section{Background}

Multiple sclerosis (MS) patients are referred to occupational therapy with complaints about fatigue, limb weakness, alteration of upper extremity fine motor coordination, loss of sensation and spasticity that causes limitations in performance of activities of daily living and social participation. The primary purpose of occupational therapy is to enable individuals to participate in self-care, work and leisure activities that they want or need to perform.

\section{Objectives}

To determine whether occupational therapy interventions in MS patients improve outcome on functional ability, social participation and/or health related quality of life.

\section{Search strategy}

We searched the Cochrane MS Group trials register (January 2003), the Cochane Central Register of Controlled Trials (CENTRAL)The Cochrane Library Issue 4, 2002, MEDLINE (January 2003), EMBASE (December 2002), CINAHL (December 2002), AMED (December 2002), SciSearch (December 2002) and reference lists of articles.

\section{Selection criteria}

Controlled (randomized and non-randomized) and other than controlled studies addressing occupational therapy for MS patients were eligible for inclusion.

\section{Data collection and analysis}

Two reviewers independently assessed the methodological quality of the included trials. Disagreements were resolved by discussion. A list proposed by Van Tulder 1997 was used to assess the methodological quality. For outcome measures, we calculated standardized mean differences. We analysed the results using a best-evidence synthesis based on type of design, methodological quality and the significant findings of outcome and/or process measures. 


\section{Main results}

One randomized clinical trial was identified and two other included studies were a controlled clinical trial and a study with a pre-post test design. The three studies involved 271 people in total. Two studies evaluated an energy-conservation course for groups of patients and one study evaluated a counseling intervention. The results of the energy conservation studies could be biased because of the designs used, the poor methodological quality and the small number of included patients. The high quality RCT on counseling reported nonsignificant results.

\section{Authors' conclusions}

On basis of this review no conclusions can be stated whether or not occupational therapy improves outcomes in MS patients.

The lack of (randomized controlled) efficacy studies in most intervention categories of occupational therapy demonstrates an urgent need for future research in occupational therapy for multiple sclerosis. Initially, a survey of occupational therapy practice for MS patients, including the characteristics and needs of these patients, is necessary to develop a research agenda for efficacy studies.

\section{PLAIN LANGUAGE SUMMARY}

\section{Occupational therapy as supportive treatment for people with multiple sclerosis}

Multiple sclerosis (MS) is a chronic disease of the nervous system which affects young and middle-aged adults. MS causes disruption of the ability of nerves to conduct electrical impulses, leading to symptoms such as muscle weakness, fatigue and loss of control over the limbs. Occupational therapy (OT) is used to try to help people with MS participate in the physical and social activities of their daily lives. The review found that there is currently no reliable evidence that OT improves outcomes for people with MS, although there was some suggestion that fatigue might be improved.

\section{B A C K G R O U N D}

Multiple sclerosis (MS) is a chronic disease of the central nervous system that represents a significant cause of disability. The disease is characterised by multiple lesions occurring in the white matter of the brain and spinal cord resulting in functional loss, including weakness, fatigue, spasticity and impairments of cognition, vision, speech, swallowing, cerebellar, bowel and bladder function (Sliwa 1998). In the Netherlands, approximately 80 out of 100,000 persons have MS (Moorer 2000).

Therapy for MS can be divided into two categories: disease modifying therapies and symptomatic or supportive therapies to optimize functional capabilities. Occupational therapy (OT) is an example of the latter category. The primary purpose of OT is to enable individuals to participate in self-care, work and leisure activities that they want or need to perform (Tipping 1994). MS patients are referred to occupational therapy with complaints of fatigue, limb weakness, alteration of upper extremity fine motor coordination, loss of sensation and spasticity that causes limitations in performance of activities of daily living. Occupational therapists instruct these patients on energy conservation, time management, efficient body mechanics and task performance, with or without assistive devices. In the Netherlands, progressive neurologic diseases such as Parkinson's disease, MS and Amyotrophic lateral sclerosis (ALS) are listed as the third most referred patient category for occupational therapy (Driessen 1997).

One non-systematic review (Ko Ko 1999) incorporated occupational therapy in the discussion of the multi-disciplinary rehabilitation for multiple sclerosis. However, this review mentioned only one study in which occupational therapy and physical therapy were the interventions under research. One meta-analysis (Baker 2001) on physical, psychological and functional interventions incorporated occupational therapy related treatments such as multidisciplinary interventions, physical therapy and social work. To our knowledge no systematic reviews of the efficacy of occupational therapy for multiple sclerosis have ever been published.

\section{O B J E C T I V E S}

To determine whether occupational therapy interventions in MS patients improve outcome on functional ability, social participation and health related quality of life. 


\section{METHODS}

\section{Criteria for considering studies for this review}

\section{Types of studies}

Studies with one of the following designs have been entered in the review.

(1) Randomised controlled clinical trial (RCT): An experiment in which investigators randomly allocate eligible people into treatment and control groups. Cross-over trials were considered as RCTs according to the Cochrane Collaboration Guidelines (Clarke 2003).

(2) Controlled clinical trial (CCT): an experiment in which eligible people are, in a non-randomized way, allocated to the treatment and the control groups.

(3) Other than controlled designs (OD): patient series and prepost studies. Such ODs can only contribute in a limited way to the best evidence synthesis.

\section{Types of participants}

Studies with patients who fulfil a clinical diagnosis (as described by the authors of the studies) of multiple sclerosis have been included.

\section{Types of interventions}

In MS, occupational therapy (OT) can include a variety of interventions. OT interventions were either regarded as "comprehensive OT" (when all six intervention categories were part of the evaluated OT treatment) or were classified into six specific intervention categories: (1) training of motor functions; (2) training of skills; (3) instruction in energy conservation skills; (4) counselling; (5) advice or instruction regarding the use of assistive devices and (6) provision of splints.

All studies were evaluated by a group of four experienced occupational therapists and reviewer CHME (see: Methods of the review). If the aforementioned OT interventions were specified in a study, then it was eligible for inclusion in this review.

\section{Types of outcome measures}

Studies that used one or more of the following outcome measures have been included.

\section{Primary outcomes}

Fatigue, pain, functional ability, social participation and quality of life.

\section{Secondary outcomes}

Knowledge about disease management, self-efficacy, motor-coordination and balance. These measures were regarded as process measures, i.e. measures considered to be indicators of a successful treatment. As will be explained below process measures can only contribute in a limited way to the best-evidence synthesis.

\section{Search methods for identification of studies}

We only considered full length articles or full written reports for inclusion in the review.

The search strategy, formulated in PubMed, has been adapted by an experienced medical librarian to make it applicable for the other databases.

\section{Electronic searches}

(1) Cochrane Multiple Sclerosis Group Trials Register (January 2003);

(2) Cochrane Central Register of Controlled Trials (CENTRAL) The Cochrane Library Issue 4, 2002; (3) MEDLINE (January 1966 until December 2002);(Appendix 3)

(4) EMBASE (January 1988 until December 2002);

(5) CINAHL (1982 until December 2002);

(6) SCISEARCH (1974 until December 2002);

(7) AMED (1985 until December 2002);

(8) The databases of the libraries of medical and rehabilitation literature of the Dutch National Institute Allied Health Professions (NPI) and of the Netherlands Institute for Health Services Research (NIVEL) (April 2002);

(9) The database of the Rehabilitation and Related Therapies (RRT) Field of The Cochrane Collaboration (May 2002).

\section{Searching other resources}

In addition, we:

(10) searched the same databases to identify reviews about the efficacy of occupational therapy in MS patients;

(11) screened the reference lists of the identified studies and reviews for additional references;

(12) contacted the authors of papers reporting studies about the effectiveness of OT in MS patients by mail and asked for any additional published studies relevant for this systematic review. A list with studies that have been identified so far was enclosed;

(13) asked authors of abstracts of possible eligible studies for a full written report.

\section{Data collection and analysis}

We performed selection for inclusion in the review, assessment of the methodological quality and data extraction in three separate 
steps. Three reviewers (EMJS, MC, CHME) took part in these procedures. Prior to all steps, two reviewers tested assessment procedures in a sample of two articles. A standard form for each step was made.

\section{Study Selection}

As we used a broad search strategy, we expected to find a large number of ineligible articles. The procedure for inclusion of the studies has been based on the recommendations by Van Tulder et. al. (Van Tulder 1997): Two reviewers (EMJS and CHME) independently performed the first selection, based on titles and abstracts. This first selection could result in probable inclusion of the study, exclusion of the study, or could be indecisive. Two reviewers (EMJS and CHME) also independently performed the second step for inclusion (definite include or exclude), using full reports and considering the criteria stated above. We resolved disagreements regarding inclusion status through discussion. If we did not reach consensus, a third reviewer (MC) decided. Finally, a group of four occupational therapists assessed the criteria for 'type of intervention' and, if appropriate classified the type of intervention into one of the six different interventions or combinations of interventions. We reached consensus through discussion.

\section{Assessment of methodological quality}

The variety in study designs included in this systematic review necessitated the use of different quality assessment tools. The methodological quality of RCTs and CCTs has been rated by a list recommended by Van Tulder et. al. (Van Tulder 1997). The list, containing specified criteria proposed by Moher (Moher 1996) and Verhagen et al (Verhagen 1998), consists of 11 criteria for internal validity, six descriptive criteria and two statistical criteria (Appendix 1). One modification was made in the specification of the criterion 'eligibility' in which the 'condition of interest' (the impairment or disability that indicated referral to occupational therapy) was added as an eligibility criterion, as proposed by Wells (Wells 2000). All criteria were scored as yes, no, or unclear. Equal weight has been applied to all items. Studies were considered to be of 'high quality' if at least six criteria for internal validity, three descriptive criteria and one statistical criterion were scored positively.

We rated the methodological quality of ODs using an adapted version of the Van Tulder list ( Van Tulder 1997). We considered some items (concerning randomization, similarity of patient groups, blinding of care-provider, blinding of patient) inapplicable to ODs and removed them from the list. We reformulated some items to make the item applicable to one patient group (for instance: “were co-interventions avoided or comparable?' was reformulated into "were co-interventions avoided?") or to make the item applicable for the design of the study (for instance: "was the outcome assessor blinded to the intervention " was reformulated into: "was the care-provider not involved in the outcome assessment?") The final list of criteria used in ODs consists of seven criteria for internal validity, four descriptive criteria and two statistical criteria (Appendix 1). We scored all criteria as yes, no, or unclear. Equal weight has been applied to all items. We considered studies to be of 'sufficient quality' if at least four out of seven criteria for internal validity, two descriptive criteria and one statistical criterion were scored positively. Of course, the distinction between ODs with a sufficient or non-sufficient quality is a relative one: the internal validity of ODs is on average substantially weaker than the internal validity of RCTs/CCTs.

Two reviewers (EMJS, MC) independently assessed the methodological quality of the included trials. We resolved disagreements by discussion. If no consensus was met a third reviewer (CHME) decided.

\section{Data extraction}

EMJS systematically extracted the following information:

(1) Study characteristics: number of participating patients, specified criteria for diagnosis of multiple sclerosis, inclusion and exclusion criteria, type of experimental and control interventions, co-interventions, features of interventions (duration, frequency, setting) and number of drop-outs.

(2) Patient characteristics: sex, age, disease duration and disease severity.

(3) Outcome and process measures assessed immediately after finishing the intervention, within six months follow up and after six or more months follow-up.

\section{Data synthesis}

For continuous variables, we computed standardized mean differences wherever possible.

For dichotomous variables, we computed odds ratios with corresponding $95 \%$ confidence intervals.

\section{Analysis of the results}

We performed separate analyses for each intervention category. The primary analysis focused on comparisons of an occupational therapy intervention with a 'no treatment' control group. However, if studies compared the effect of more than two intervention groups, two reviewers (EMJS, CHME) decided by consensus, how these comparisons had to be classified. In particular, if two interventions were compared, the predominant contrast needed to be the occupational therapy treatment provided.

We expected to find a lot of diversity among studies with regard to patients (severity of the disease), interventions (duration, frequency and setting) and outcome measures (diversity, presentation of the results) to make quantitative analysis (meta-analysis) appropriate. Instead, we performed a best evidence synthesis by attributing various levels of evidence to the efficacy of occupational therapy, taking into account the design of the studies, the methodological quality and the outcome of the original studies. The best-evidence synthesis (Appendix 2) is based upon the one proposed by Van Tulder et. al. (Van Tulder 2002) and we adapted this for the purpose of this review.

We performed sensitivity analyses by attributing different levels of methodological quality to the studies:

(1) excluding low quality studies; and 
(2) considering studies to be of "high quality " if four or more criteria of internal validity were met.

\section{RE S U L T S}

\section{Description of studies}

See: Characteristics of included studies; Characteristics of excluded studies.

\section{Description of studies}

The search strategy resulted in a list of 420 citations. After inclusion on title, abstract and full article, three (Mathiowetz 2001; O'Hara 2002; Vanage 2003) out of six identified OT studies fulfilled all inclusion criteria. The Mathiowetz study was an uncontrolled repeated time series, O' Hara reported on a randomized clinical trial whereas the Vanage study used a controlled clinical trial design. See "Table: Characteristics of Included Studies".

\section{Education in energy conservation}

Two studies evaluated the impact of an energy conservation course for groups of multiple sclerosis patients on fatigue. The energy conservation course used in the CCT (Vanage 2003) was adapted from the energy conservation course used in the OD (Mathiowetz 2001). The CCT had one hour sessions in an eight weeks course with three to eight participants while the OD evaluated sessions of Education of energy conservation

The CCT (Vanage 2003) had a low methodological quality. However, given the methodological constraints of ODs, the study by Mathiowetz 2001 was of sufficient methodological quality to be included.

\section{Counselling}

The RCT (O'Hara 2002) had a high methodological quality. Important items such as allocation concealment and blinding of outcome assessor were fulfilled in this study.

\section{Effects of interventions}

See: Table 2, results on fatigue, functional ability and social participation. two hours for six weeks with eight to ten participants. Additionally, the Mathiowetz study evaluated also the outcome measures: functional ability, social participation and self-efficacy. Assessments in the OD (Mathiowetz 2001) were performed six weeks before the start of the course, at the start of the course, at the end of the course and at six weeks follow-up. The Vanage study measured before and at the end of the course and at eight weeks follow-up. The comparison of treatment was made with a socializing group. Counselling

One RCT (O'Hara 2002) evaluated a program in which two discussion sessions about self-care strategies were applied to MS patients living in the community. One session took one to two hours and was individually or group based. The study evaluated the outcome measures: fatigue, pain, functional ability and social participation. Assessments were performed at baseline and six months after the start of the trial. The comparison was made with a nontreated control group.

Three OT studies were excluded. One study (Aisen 1993) was excluded as patients who had suffered a traumatic brain injury were included, and the other two (Morris 1991; Bowcher 1998) because of the use of a single-subject design. See "Table: Characteristics of Excluded studies“.

\section{Risk of bias in included studies}

See: Table 1, Assessed Methodological quality. 


\section{Education in energy conservation}

Fatigue was measured in both studies. The CCT (Vanage 2003) reported a statistically significant decrease of impact of fatigue (effect size $-0.75 ; 95 \%$ confidence interval -1.42 to 0.07$)$. Mathiowetz 2001 reported significant differences $(\mathrm{P}<0.01)$ for the pre-post intervention comparison. This decrease of fatigue impact was maintained at six weeks follow-up.

Mathiowetz 2001 reported non-significant results on functional ability. On social participation, a significant difference between pre -and post-test was reported which was maintained at six weeks follow-up. Mathiowetz 2001 also assessed the process measure selfefficacy and presented a statistically significant increase in selfefficacy that lasted at six weeks follow-up (Table 3).

Applying the best evidence synthesis to these data we concluded that there is insufficient evidence for the efficacy of an energy conservation course for multiple sclerosis patients.

\section{Counselling}

Fatigue, pain, functional ability and social participation were measured in the RCT (O'Hara 2002) and showed no statistically significant differences between the intervention and the control group. Thus, there is no evidence for the efficacy of Counselling based on one RCT.

The sensitivity analyses do not alter these conclusions (data not shown).

\section{DISCUSSION}

Although two of the three studies included in this review reported efficacy of occupational therapy, there is insufficient evidence to support or refute the efficacy of occupational therapy for multiple sclerosis patients. Both studies were non-RCTs and had a small number of included patients. These two identified studies evaluated a specific OT intervention, namely an energy conservation course for groups. Only one study on Counselling was found and it showed no evidence for the efficacy of this intervention. We did not identify any other studies for the other interventions.

Our results do not correspond with the findings of a meta-analysis (Baker 2001) on the efficacy of OT-related treatments for MS patients. Their review on physical, psychological and functional interventions incorporated 23 studies on OT related treatments such as multi-disciplinary interventions, physical therapy and social work. In our review we only included OT interventions. Furthermore, we excluded studies because of the use of a single-case design or because of the inclusion of patients with other diseases than MS in the original study. These differences in inclusion criteria might clarify the large dissimilarity in the amount of included studies in both reviews. Other differences were the methodological choices made. Baker et al. (Baker 2001) presented an overall medium effect size $(r=0.52)$. On the basis of the diversity between patients, interventions and outcome measures, we chose to use a qualitative best-evidence synthesis instead of performing a quantitative meta-analysis and to analyse results per outcome dimension. In our opinion the latter is a better way of dealing with large diversity and hetereogeneity. We question whether the efficacy of occupational therapy can be based on non-OT studies and therefore, in our opinion, the results of our review provide a better estimate of the efficacy of OT.

The lack of occupational therapy efficacy studies in MS patients should be of great concern. It is well known that MS is a progressive disease with a high impact on functional ability and participation. In multi-disciplinary rehabilitation the role of OT is well recognized (Feigenson 1981; Di Fabio 1997; Freeman 1997). OT aims at the consolidation of functional abilities and participation despite the expected decline in physical functions and abilities which is often seen in progressive diseases.

If OT has an important role in the efficacy of multi-disciplinary rehabilitation, why are there so few OT studies? One possible reason is that is may be difficult to clearly distinguish two different OT treatment methods in a RCT. Furthermore, a comparison between a treated and a non-treated control group seems to be even more difficult because it is often considered unethical to exclude people with a progressive disease from treatment. In addition, most of the MS patients are treated in a multi-disciplinary context which makes it difficult to control for co-interventions. These arguments might provide some of the answers to the question why the efficacy of OT for MS patients is so rarely studied.

Although clinical guidelines are formulated (Richer 1999) for the OT treatment of neuro-degenerative diseases including MS, the treatment recommended is not evidence based. Furthermore, little is known about the characteristics and needs of MS patients referred to OT, goals set in the OT-treatment, specific interventions applied to reach those goals, and outcomes important to patients and occupational therapists. Initially, a survey of occupa- 
tional therapy practice for multiple sclerosis patients including the characteristics and needs of these patients is necessary to develop a research agenda for efficacy studies.

\section{A U T HOR S' CONCLUSIONS Implications for practice}

On basis of this review, no conclusions can be stated whether or not occupational therapy improves outcomes in multiple sclerosis patients. Although two studies presented outcomes favouring occupational therapy, these results are possibly biassed due to methodological flaws.

\section{Implications for research}

The lack of randomized controlled efficacy studies in most intervention categories of occupational therapy shows an urgent need for future research in occupational therapy for multiple sclerosis. A survey addressing the questions: which MS patients are treated in
OT; which of their problems should be addressed within OT treatment; what goals are relevant; what are the interventions applied by occupational therapist to reach these goals; which outcomes are important to both MS patients and occupational therapists; will give more insight into OT practice for multiple sclerosis. On the basis of this information, specific efficacy questions can be formulated and examined with the best possible methodological design. A high methodological quality and sufficient statistical power are two important issues in planning future research.

\section{ACKNOWLEDGEMENTS}

This study is funded by a grant from the Dutch Health Care Council (College voor Zorgverzekeringen(CVZ)).

The authors would like to thank Mrs.P.Moons and Mrs.N.van de Kolk for discussing occupational therapy issues and Mrs. R van den Berg for making the search strategy applicable to all the searched databases.

\section{R E F E R E N C E S}

\section{References to studies included in this review}

Mathiowetz 2001 \{published data only\}

Mathiowetz V, Matuska KM, Murphy ME. Efficacy of an energy conservation course for persons with multiple sclerosis. Archives of Physical Medicine and Rehabilitation 2001;82(4):449-56.

\section{O'Hara 2002 \{published data only\}}

O’Hara L, Cadbury H, De Souza L, Ide L. Evaluation of the effectiveness of professionally guided self-care for people with multiple sclerosis living in the community: a randomized controlled trial. Clinical Rehabilitation 2002; 16(2):119-28.

Vanage 2003 \{published data only\} Vanage SM, Gilbertson KK, Mathiowetz V. Effects of an energy conservation course on fatigue impact for persons with progressive multiple sclerosis. American Journal of Occupational Therapy 2003;57(3):315-23.

\section{References to studies excluded from this review}

Aisen 1993 \{published data only\}

Aisen ML, Arnold A, Baiges I, Maxwell S, Rosen M. The effect of mechanical damping loads on disabling action tremor. Neurology 1993;43(7):1346-50.

Bowcher 1998 \{published data only\} Bowcher H, May M. Occupational therapy for the management of fatigue in multiple sclerosis. British Journal of Occupational Therapy 1998;61(11):488-92.
Morris 1991 \{published data only\}

Morris PA. A habituation approach to treating vertigo in Occupational therapy. The American Journal of Occupational Therapy 1991;45(6):556-8.

\section{Additional references}

\section{Baker 2001}

Baker NA, Tickle-Degnen L. The effectiveness of physical, psychological, and functional interventions in treating clients with multiple sclerosis: a meta-analysis. American Journal of Occupational Therapy 2001;55(3):324-31.

\section{Clarke 2003}

Clarke M, Oxman AD, editors. Analysing and presenting results. Cochrane Reviewers Handbook 4.1.6; Section 8. In: The Cochrane Library [database on disk and CDROM]. The Cochrane Collaboration. Oxford: Update Software; 2003.

Di Fabio 1997

Di Fabio RP, Choi T, Soderberg J, Hansen CR. Health related quality of life for patients with progressive multiple sclerosis: influence of rehabilitation. Physical Therapy 1997; 77(12):1704-16.

Driessen 1997

Driessen MJ, Dekker J, Lankhorst GJ, Van der Zee J. Occupational therapy for patients with chronic diseases. Disability and Rehabilitation 1997;19(5):198-204.

\section{Feigenson 1981}

Feigenson JS, Scheinberg L, Catalano RN, Polkow L, Mantegazza PM, Feigenson WD, et al.The cost-effectiveness 
of multiple sclerosis rehabilitation: a model. Neurology 1981;31(10):1316-22.

\section{Freeman 1997}

Freeman JA, Langdon DW, Hobart JC, Thompson AJ. The impact of inpatient rehabilitation on progressive multiple sclerosis. Annals of Neurology 1997;42(2):236-44.

\section{Ko Ko 1999}

Ko Ko C. Effectiveness of rehabilitation for multiple sclerosis. Clinical Rehabilitation 1999;13 Suppl (1):33-41.

\section{Moher 1996}

Moher D, Jadad AR, Tugwell P. Assessing the quality of randomized controlled trials. Current issues and future directions. International Journal of Technology Assessment in Health Care 1996;12(2):195-208.

\section{Moorer 2000}

Moorer P, Suurmeijer ThPBM, Zwanikken CP. Health care utilization by people with multiple sclerosis in the Netherlands: results of two separate studies. Disability and Rehabilitation 2000;22(16):695-701.

\section{Richer 1999}

Richer CB, Bhasin CA. Occupational therapy practice guidelines for adults with neurodegenerative disease. Bethesda Maryland: AOTA, 1999.

\section{Sliwa 1998}

Sliwa JA, Cohen BA. Multiple sclerosis. In: Delisa JA, Gans BM editor(s). Rehabilitation Medicine: principles and practice. 3rd Edition. Philadelphia: Lippincott-Raven, 1998:1241-57.

\section{Tipping 1994}

Tipping L. Multiple Sclerosis. In: Turner A, Foster M, Johnson SE editor(s). Occupational therapy and physical dysfunction. 4th Edition. New York: Churchill Livingstone, 1994:497-512.

\section{Van Tulder 1997}

Van Tulder MW, Assendelft WJJ, Koes BW, Bouter LM. Method guidelines for systematic reviews in the Cochrane Collaboration back review group for spinal disorders. Spine 1997;22(20):2323-30.

\section{Van Tulder 2002}

Van Tulder MW, Cherkin DC, Berman B, Lao L, Koes BW. Accupuncture for low back pain. Cochrane Database of Systematic Reviews 2002, Issue 1. [DOI: DOI: 10.1002/ 14651858.]

\section{Verhagen 1998}

Verhagen AP, De Vet HCW, De Bie RA, Kessels AGH, Boers $\mathrm{M}$, Bouter LM, et al.The delphi list: a criteria list for quality assessment of randomized clinical trials for conducting systematic reviews developed by delphi consensus. Journal of Clinical Epidemiology 1998;51(12):1235-41.

\section{Wells 2000}

Wells GA, Shea B, OConnell D, Peterson J, Welch V, Tugwell P. The Newcastle-Ottawa scale (NOS) for assessing the quality of non-randomized studies in meta-analyses. Proceedings of the $3 \mathrm{rd}$ symposium on systematic reviews. 2000: The instrument with the manual can be found on www.lri.ca.

* Indicates the major publication for the study 


\section{CHARACTERISTICS OF STUDIES}

\section{Characteristics of included studies [ordered by study ID]}

Mathiowetz 2001

\begin{tabular}{|c|c|c|}
\hline Methods & \multicolumn{2}{|l|}{ Repeated time serie } \\
\hline Participants & \multicolumn{2}{|c|}{$\begin{array}{l}\text { MS > } 18 \text { years of age, FSS score } 4>\text {, live in community } \\
N=54\end{array}$} \\
\hline Interventions & \multicolumn{2}{|c|}{ energy conservation course 2 hours for 6 weeks } \\
\hline Outcomes & \multicolumn{2}{|l|}{$\begin{array}{l}\text { FIS } \\
\text { SF-36 } \\
\text { self-efficacy }\end{array}$} \\
\hline Notes & \multicolumn{2}{|c|}{ measured at 6 weeks and 12 weeks from pre-test } \\
\hline \multicolumn{3}{|l|}{ Risk of bias } \\
\hline Item & Authors' judgement & Description \\
\hline Allocation concealment? & Unclear & D - Not used \\
\hline
\end{tabular}

\section{O’Hara 2002}

\begin{tabular}{|c|c|c|}
\hline Methods & \multicolumn{2}{|c|}{ Randomized controlled trial } \\
\hline Participants & \multicolumn{2}{|c|}{$\begin{array}{l}\text { MS, confirmed by general practitioner } \\
\mathrm{N}=183\end{array}$} \\
\hline Interventions & \multicolumn{2}{|c|}{$\begin{array}{l}\text { discussion of self-care strategies, 1-2 hours, } 2 \text { times. } \\
\text { non treated control group }\end{array}$} \\
\hline Outcomes & \multicolumn{2}{|l|}{$\begin{array}{l}\text { mobility } \\
\text { SF -36 } \\
\text { Barthel Index }\end{array}$} \\
\hline Notes & \multicolumn{2}{|c|}{ measured 6 months from base-line } \\
\hline \multicolumn{3}{|l|}{ Risk of bias } \\
\hline Item & Authors' judgement & Description \\
\hline Allocation concealment? & Yes & A - Adequate \\
\hline
\end{tabular}


Vanage 2003

\begin{tabular}{|c|c|c|}
\hline Methods & \multicolumn{2}{|l|}{ Controlled Clinical trial } \\
\hline Participants & \multicolumn{2}{|c|}{$\begin{array}{l}\text { MS, EDSS } 5,5>\text {, cognition scale } 4>\text {, FIS } 4>\text {, minimal } 5 \\
\text { sessions } \\
N=37\end{array}$} \\
\hline Interventions & \multicolumn{2}{|c|}{ energy conservation course 1 hour for 8 weeks, control group followed support session led by chaplain } \\
\hline Outcomes & \multicolumn{2}{|l|}{ FIS } \\
\hline Notes & \multicolumn{2}{|c|}{ measured at 8 weeks and 16 weeks from pre-test } \\
\hline \multicolumn{3}{|l|}{ Risk of bias } \\
\hline Item & Authors' judgement & Description \\
\hline Allocation concealment? & Unclear & D - Not used \\
\hline
\end{tabular}

D: allocation concealment not used

EDSS: Expanded Disability Status Scale

FIS: Fatigue Impact Scale

FSS: Fatigue Severity Scale

SF-36: Medical Outcome study short-form Health survey, used were the subscales physical functioning (for functional ability), social functioning (for social participation), vitality (for fatigue) and pain

Characteristics of excluded studies [ordered by study ID]

\begin{tabular}{ll}
\hline Study & Reason for exclusion \\
\hline Aisen 1993 & Included patients with disease other than multiple sclerosis \\
\hline Bowcher 1998 & Single case design \\
\hline Morris 1991 & Single case design \\
\hline
\end{tabular}


DATA AND ANALYSES

This review has no analyses.

ADDITIONAL TABLES

Table 1. Assessed methodological quality

\begin{tabular}{|c|c|c|c|c|c|}
\hline Study ID & Design & Internal validity & Descriptive & Statistical & Meth. quality \\
\hline Mathiowetz 2001 & OD & $\begin{array}{l}6,7,10,14 \\
\text { Appendix } 1 \text { for items) }\end{array}$ & $\begin{array}{l}\text { 4, 13a (see Appendix } 1 \\
\text { for items) }\end{array}$ & $\begin{array}{l}\text { 15, } 17 \text { (see Appendix } 1 \\
\text { for items) }\end{array}$ & sufficient \\
\hline O’Hara 2002 & RCT & $\begin{array}{l}2 \mathrm{a}, 2 \mathrm{~b}, 9,10,12,14 \text { (see } \\
\text { Appendix } 1 \text { for items) }\end{array}$ & $\begin{array}{l}3,4,13 a \text { (see Appendix } \\
1 \text { for items) }\end{array}$ & $\begin{array}{l}15,17 \text { (see appendix } 1 \\
\text { for items) }\end{array}$ & high \\
\hline Vanage 2002 & CCT & $\begin{array}{l}10 \text { (see Appendix } 1 \text { for } \\
\text { items) }\end{array}$ & $\begin{array}{l}\text { 13a (see Appendix } 1 \text { for } \\
\text { items) }\end{array}$ & $\begin{array}{l}15,17 \text { (see appendix } 1 \\
\text { for items) }\end{array}$ & low \\
\hline
\end{tabular}

Table 2. Results on fatigue, functional ability and quality of life

\begin{tabular}{|c|c|c|c|c|c|}
\hline Study ID & Design & Fatigue & Pain & Functional ability & Social participation \\
\hline Mathiowetz 2001 & OD & $\begin{array}{l}\mathrm{p}<0.001 \text { within group } \\
\text { pre-test/post test }\end{array}$ & not tested & $\begin{array}{l}\mathrm{p}>0.05 \text { within group } \\
\text { pre-test/post test }\end{array}$ & $\begin{array}{l}\mathrm{p}<0.01 \text { within group } \\
\text { pre-test/post test }\end{array}$ \\
\hline O'Hara 2002 & RCT & $0.27[-0.04$ to 0.58$]$ & $\begin{array}{l}\text { SMD } 0.10 ; 95 \%-0.20 \\
\text { to } 0.41\end{array}$ & $\begin{array}{l}\text { SMD } 0.08 ; 95 \% \mathrm{CI}- \\
0.23 \text { to } 0.38\end{array}$ & $\begin{array}{l}\text { SMD } 0.09 ; 95 \% \text { CI - } \\
0.21 \text { to } 0.40\end{array}$ \\
\hline Vanage 2002 & CCT & $\begin{array}{l}\text { SMD }-0.75 ; 95 \% \text { CI- } \\
1.42 \text { to }-0.07\end{array}$ & not tested & not tested & not tested \\
\hline
\end{tabular}

Table 3. Results on fatigue, functional ability and quality of life at follow up

\begin{tabular}{lllll}
\hline Study ID & Design & Fatigue & Functional ability & Quality of life \\
\hline Mathiowetz 2001 & OD & $\begin{array}{l}\mathrm{p}<0.001 \text { within group pre-test/ } \\
\text { post test }\end{array}$ & $\begin{array}{l}\mathrm{p}>0.05 \text { within group pre-test } / \\
\text { post test }\end{array}$ & $\begin{array}{l}\mathrm{p}<0.01 \text { within group pre-test/ } \\
\text { post test }\end{array}$ \\
\hline
\end{tabular}




\section{FEE D B A C K}

\section{Occupational therapy for multiple sclerosis}

\section{Summary}

Young, active MS patients strikingly often complain about fears to perform strenous tasks which their professional life requires. Lifting, in fact any kind of abrupt general effort may thus result in a sudden aggravation of the incapacitations which they are particularly prone to.

During the last fifty years, his peculiarity of MS seems to have fallen more and more into oblivion.

\section{Reply}

Dr. Schelling stresses an important issue regarding occupational performance in MS patients. Although occupational therapy's focus on activities is much broader than work related activities it is known that strenuous tasks may aggravate MS symptoms. Research in occupational therapy for MS is very rare and focuses until now primarily on fatigue management. Which means that patients are guided to find a balance between physical exertion and relaxation. We discussed in our review that little is known about the characteristics and needs of MS clients referred to occupational therapy. In our view, it is very important to focus on client centred outcomes in future research, including finding ways to perform strenuous tasks if necessary.

\section{Contributors}

Comment received from: Franz A. Schelling - January 2006

Reply from: Steultjens EMJ, Dekker J, Bouter LM, Cardol M, Van de Nes JCM, Van den Ende CHM (Review authors) - March 2006 Processed by: Dean Marko Wingerchuk (Feedback Editor) - March 2006

\section{WHAT'S NEW}

Last assessed as up-to-date: 21 May 2003.

\begin{tabular}{lll}
\hline Date & Event & Description \\
\hline 23 June 2008 & Amended & Converted to new review format. \\
\hline
\end{tabular}

\section{H IS TOR Y}

Protocol first published: Issue 2, 2002

Review first published: Issue 3, 2003

\begin{tabular}{lll}
\hline Date & Event & Description \\
\hline 3 October 2006 & Feedback has been incorporated & Feedback from FA Schelling added along with reply from the authors \\
\hline
\end{tabular}




\section{CONTRIBUTIONS OFAUTHORS}

EMJ Steultjens is the researcher on this project and author of the review. J Dekker, LM Bouter and Mrs CHM van den Ende are her supervisors and discussed the protocol, the data collection, all results and the conclusions. EMJS and CHME took part in the inclusion procedure. Mrs M Cardol, occupational therapist, discussed occupational therapy issues and took part with EMJS and CHME in the rating of the methodological quality. JCM van de Nes, neurologist, checked the review on medical relevant issues. All authors approved the final version of this review.

\section{DECLARATIONS OF INTEREST}

None known to the authors.

\section{SOURCES OF SUPPORT}

\section{Internal sources}

- No sources of support supplied

\section{External sources}

- Dutch Health Care Council (College voor Zorgverzekeringen (CVZ)), Netherlands.

\section{NDEX TERMS}

\section{Medical Subject Headings (MeSH)}

*Occupational Therapy; Multiple Sclerosis [ ${ }^{*}$ rehabilitation]; Randomized Controlled Trials as Topic

\section{MeSH check words}

Humans 